\title{
Effect of PFI mill and Valley beater refining on cellulose degree of polymerization, alpha cellulose contents, and crystallinity of wood and cotton fibers
}

\author{
Le Van $\mathrm{Hai}^{1}$, Hee Jung Park ${ }^{1}$ and Yung Bum Seo ${ }^{\dagger}$
}

Received July 21, 2013; Received in revised form August 9, 2013; Accepted August 14, 2013

\begin{abstract}
Manufacturing fabrics from dissolving cellulosic pulp is increasing in these days. For making high quality of cellulose-based fabrics, control of cellulose DP (degree of polymerization), its alpha cellulose content, its brightness, and its crystallinity are important. To process the cellulosic raw material, refining of cellulosic fibers is essential, and it is important to know if refining affects those important cellulose properties. The effects of PFI mill and Valley beater refining on the alpha-cellulose content, cellulose DP, crystallinity, and paper mechanical properties of wood and two different cotton fibers were studied. The results showed that PFI mill refining rarely affected those properties. Fibers refined by a Valley beater displayed a small reduction in fiber length in comparison with those refined by a PFI mill. However, the Valley beater refining method produced almost no changes in cellulose properties, either. The refining process seemed to have very little effect on the cellulose DP, crystallinity index, or alpha-cellulose content until the freeness decreased to around $300 \mathrm{~mL}$ CSF for wood and $100 \mathrm{~mL}$ CSF for cotton fibers, respectively. There were also no differences in tensile strength development in two refining methods.
\end{abstract}

Keywords: PFI mill, Valley beater, softwood, hardwood, cotton fibers, alpha-cellulose, crystallinity, cellulose DP

\section{Introduction}

Hardwood, softwood, and non-wood fibers generate natural fibers that grow in almost all areas of the world. Wood and non-wood fibers are used to produce papers, packaging materials, corrugated containers, and other products. Manufacturing fabrics from dissolving pulp is also increasing in these days. For making high quality fabrics from cellulose, some intrinsic factors including its DP, alpha cellulose content, brightness, and crystallinity index must be considered. Refining of cellulosic fibers is also

- Professor. Dept. of Bio-based Materials, Chungnam National Univ., Republic of Korea.

1 Graduate student. Dept. of Bio-based Materials, Chungnam National Univ., Republic of Korea.

$\dagger$ 교신저자 (Corresponding author) : E-mail : ybseo@cnu.ac.kr 
essential in processing the cellulosic raw materials, and it is important to know if refining affects those important cellulose properties. In general, refining increases fiber internal and external fibrillation and flattens the fibers and fiber surface areas, thus increasing the accessibility of the fiber surface and the bonding between the fibers. There are many types of refining processes that are applied at different paper mills for different purposes at different stages, using different setups and layouts. According to Jorma1, refining is one of the most important unit processes to increase the paper and paper-board quality in papermaking. He also notes that refining improves the fiber-bonding ability and smoothness, and sometimes shortens the fibers to facilitate good formation. Changes in the refining conditions such as consistency, time, energy, and other factors also affect the development of fiber properties. ${ }^{1)}$ Wood and non-wood fibers can be refined in low, medium, and high consistency and mixed systems in order to meet the requirements of the final product. Alessandro et al. ${ }^{2)}$ reported that refining is an important process to increase the bonding between fibers by collapsing them and producing fibrillation in them, thus increasing the fiber surface contact area and bonding. After studying the effect of beating on recycled eucalyptus fibers, Yangmei et al. ${ }^{3)}$ concluded that the crystallinity of cellulose increased at the beginning and then decreased with an increase in the degree of beating. In their work, the authors used a PFI mill at a $6 \%$ pulp consistency. Tonoli et al. ${ }^{4)}$ reported that wood fibers treated by a Bruno disc refiner and chemical treatment resulted in decreased pulp crystallinity. They further reported that the crystallinity of pulp fibers was reduced from $69 \%$ to $60 \%$ by using the Bruno disc refiner. Moreover, they indicated that this decrease in crystallinity could reduce the fiber stiffness. They concluded that the decrease in crystallinity was caused by the high shearing action in the refining treatment. According to Jean-Luc et al.," the tensile properties of cellulose fibers increase with the increase in degree of polymerization, crystallinity, and orientation. It is, therefore, important to evaluate the changes in crystallinity, viscosity, and alpha-cellulose content after refining, since they affect the strength properties of many products. Despite the importance of the subject, publications and studies on cotton fiber refining and its effects on viscosity, alpha-cellulose content, and crystallinity are rare. Cotton has very long fibers that are difficult to refine. Alejandro et al. ${ }^{6}$ carried out research on the refining of cotton linter to be used in high-quality artistic papers and conservation papers. They noted that the refining of cotton fibers results in high energy consumption. In order to refine cotton linter fibers, they used several additives and chemicals to improve the refining results obtained using a Valley beater. Nahed ${ }^{7}$ carried out research on cotton fiber refining using both hot and cold chemical treatments. According to their study, the hot and cold chemical treatments increased the alpha-cellulose content by removing short chain carbohydrates. Nahed further reported that the AQ (anthraquinone) treatment used in the pulping process with hot chemicals increased the alpha-cellulose content and yield owing to AQ's effect of stabilizing the dissolution of carbohydrates. His research indicated that the alpha-cellulose content reached up to $99.3 \%$ with cold chemical refining and $99.1 \%$ with hot chemical refining. Nahed also noted that the crystallinity did not seem to be changed much by either the hot or cold chemical treatment. John ${ }^{8)}$ presented the effects of refining on viscosity, on the basis of an experiment in which the viscosity of pulp was decreased by shortening the fibers under lowconsistency refining. The author used a consistency of 2.5 to $5 \%$ in the pulp refining process and checked the viscosity. According to John, the decrease in viscosity was due to fiber length shortening that took place in the low- consistency refining. According to Kim et al., ${ }^{9}$ the higher the DP, crystallinity index and crystalline size, the better the thermal degradation protection. Jean-Luc et al. ${ }^{10)}$ noted that the mechanical degradation of cellulose has not been studied as much as the 
chemical, radiation, thermal degradation of cellulose. They postulated that mechanical processes might reduce crystallinity and chain cleavage.

As mentioned earlier, there has been fewer research on the effects of refining on the alpha-cellulose content, viscosity, and crystallinity of wood and non-wood fibers. For this reason, the present research focuses on changes of these properties by refining for the cases of hardwood, softwood, and cotton fibers

\section{Materials and Methods}

\subsection{Materials}

In this research, four types of raw materials were used: hardwood, softwood, and two different types of cotton fibers. The cotton fiber samples were collected in a pad form from KOMSCO in Korea. The hardwood and softwood fibers were collected from a papermaking mill in Korea. Information on the fibers is presented in Table 1 . The testing methods used in this study are listed in Table 2.

\subsection{Methods}

The cotton fibers were taken in reduced DPs, and the fibers were in pad form. All materials were soaked into water for four hours before being disintegrated and refined. The PFI mill was used at a consistency of $10 \%$. The Valley beater was used to refine the softwood fiber and Cotton 1 for comparison at a consistency of around 1.5\%. An X-Ray diffractometer (XRD, Model D8 Advance, Bruker AXS) was used to measure the crystallinity of the samples after air drying. The measurements were carried out from $5^{\circ}$ to $60^{\circ}$ with a step size of $0.02^{\circ}$. The XRD was operated at $40 \mathrm{kV}$ and $40 \mathrm{~mA}$. The crystallinity index was calculated using the Segal method. For fiber length measurement, a Lorentzen \& Wettre fiber analyzer was used. The handsheet basis weight was $60 \mathrm{~g} / \mathrm{m}^{2}$. Handsheet samples were placed in an air-conditioned room $\left(20^{\circ} \mathrm{C}, 50 \% \mathrm{RH}\right)$ for one day before their physical properties were examined. Diagrams of the process are presented in Fig. 1.

\section{Table 1. Fiber information}

\begin{tabular}{ccl}
\hline Fibers & $\begin{array}{c}\text { Viscosity } \\
\text { as received (cp) }\end{array}$ & Origin \\
\hline Hardwood & 14.6 & $\begin{array}{l}\text { Mixture of Aspen and Poplar from Canada } \\
\text { Bleached kraft pulp }\end{array}$ \\
\hline Softwood & 15.6 & $\begin{array}{l}\text { Mixture of Hemlock, Douglas fir, and Cedar from Canada } \\
\text { Bleached kraft pulp }\end{array}$ \\
\hline Cotton 1 & 5.4 & Cotton linter 1 from KOMSCO (Korea Minting \& Security Printing Corporation) \\
\hline Cotton 2 & 24.5 & Cotton linter 2 from KOMSCO \\
\hline
\end{tabular}

Table 2. Testing methods used

\begin{tabular}{ll}
\hline \multicolumn{1}{c}{ Test name / Equipments } & Used methods / standard \\
\hline Freeness & T227 om-92 \\
\hline Alpha cellulose content & KS M 7044 \\
\hline PFI mill & T 248 cm-85 \\
\hline Valley beater & T 200 om-89 \\
\hline Viscosity (Cupriethylene diamine method) & T 230 om-89 \\
\hline Crystallinity & X-Ray diffraction / Segal method \\
\hline Tensile test & T 404/ T 494 \\
\hline Handsheet former & T 205om-88 \\
\hline Fibers length / Lorentzen \& Wettre fiber analyzer & ISO 16065-2 \\
\hline Physical testing of pulp handsheets & T 220 om-88
\end{tabular}




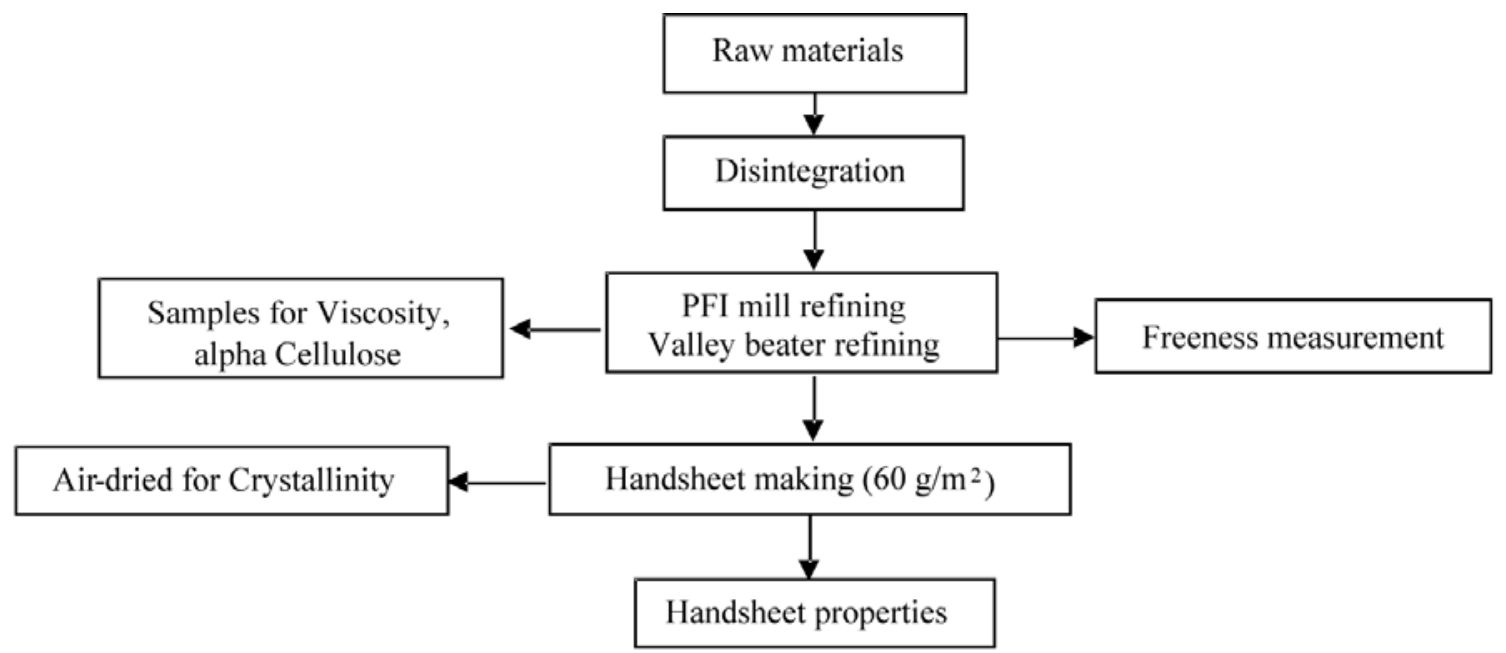

Fig. 1. Refining procedure.

\section{Results and Discussion}

\subsection{Effect of refining on pulp viscosity}

Fig. 2(a) indicated viscosities of the samples, where viscosities of all samples changed very little regardless of refining time. This means that heavy refining down to $300 \mathrm{~mL}$ CSF did not cause significant CED viscosity drops (or DP drops) for either wood fibers or cotton fibers. The fiber lengths of all four samples under four different refining levels were also indicated in Fig. 2(b). There were no noticeable fiber length changes by PFI mill refining, but the decrease in fiber length was shown for Cotton 1 in Valley beater refining. It is believed that low viscosity causes low fiber strength. Cotton 1 had the lowest viscosity in Fig. 2(a), which may lead to the lowest fiber strength. At $10 \%$ consistency, there are more fibers in contacts between the housing surface and the rotor bar in PFI mill, but at $1.5 \%$ consistency, there are more fibers to metal contacts in Valley beater. Low consistency refining with Valley beater may have caused fiber cutting for the low strength fibers. On the other hand, it is reasonable to expect reduced DP or CED viscosity by the shortened or cut fibers such as Cotton 1 by Valley beater refining, but no change of viscosity was seen in Fig. 2(a). Therefore, it may be said that fiber shortening or cutting may not cause large change of viscosity if the fiber shortening was not extreme during refining.

The fiber length of Cotton 1 was decreased very fast by Valley beater refining from $1.127 \mathrm{~mm}$ to 0.687 during 30 minute refining time, and then slowly decreased to $0.611 \mathrm{~mm}$ after 45 minutes refining time. For softwood sample, its fiber length seemed not to change much by Valley beater refining; its fiber length was initially $2.346 \mathrm{~mm}$ and was decreased to 2.205 $\mathrm{mm}$ after 170 minutes refining. There was more fiber shortening in Valley beater refining than in PFI refining for Cotton 1.

\subsection{Effect of refining on alpha-cellulose content}

Alpha-cellulose content is an important factor in making natural-fiber-based fabrics from cellulose sources. A high alpha-cellulose content indicates a greater presence of high DP cellulose, which in turn may facilitate the making of strong fabrics. The initial alpha-cellulose contents of our four samples were 99.4\% for Cotton 2, 97.8\% for Cotton 1, 89.2\% for softwood, and $85.7 \%$ for hardwood pulp. After 30 minutes of refining, there were just small changes in 


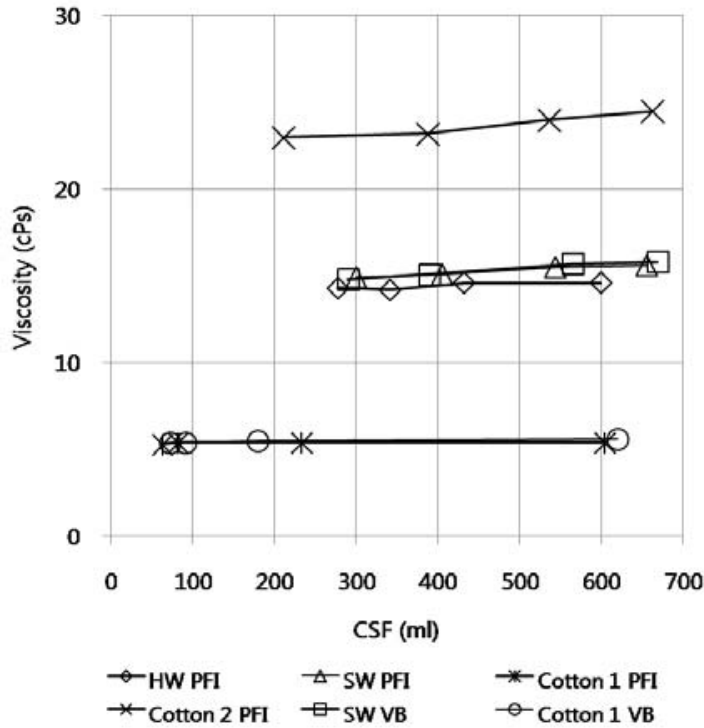

(a) Viscosity of pulp samples

SW PFI: Softwood refined by PFI mill

Cotton 1 VB: Cotton linter 1 refined by Valley beater Cotton 1 PFI: Cotton linter 1 refined by PFI mill

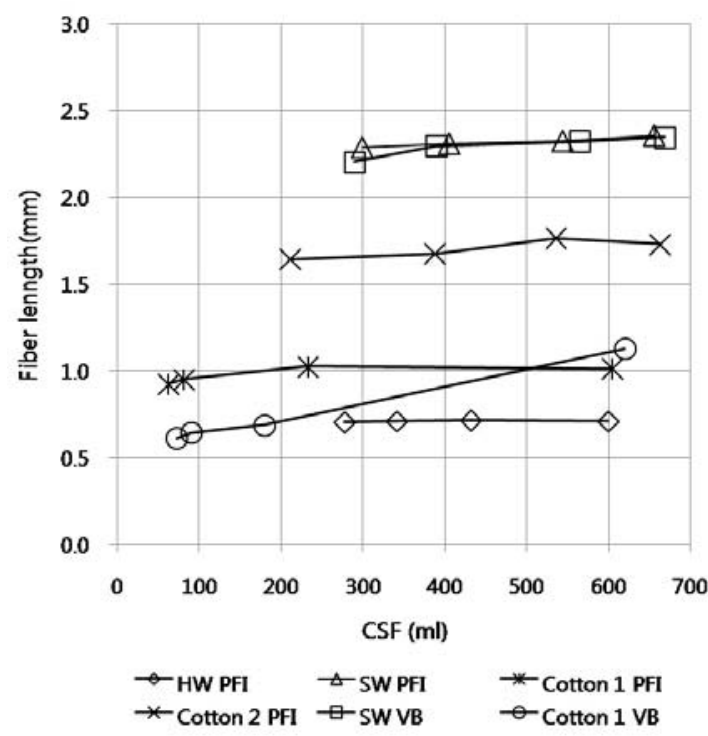

(b) fiber length of pulp samples

SW VB: Softwood refined by Valley beater HW PFI: Hardwood refined by PFI mill Cotton 2 PFI: Cotton linter 2 refined by PFI mill

Fig. 2. Effect of PFI mill and Valley beater refining on viscosity, and fiber length.

the alpha-cellulose content, with values of $99.0 \%$, 97.9\%, 89.7\% and $86.2 \%$ for Cotton 2, Cotton 1, softwood pulp, and hardwood pulp, respectively. There was almost no change in the alpha-cellulose content after treatment by the PFI mill, as shown in Fig. 3. Fig. 3 also shows the effects of Valley beater refining on alpha-cellulose contents, which also produced almost no changes in the alpha-cellulose content.

\subsection{Effects of refining on crystallinity of pulp fibers}

Tonoli et al. ${ }^{4)}$ reported that the crystallinity of pulp fibers decreased from $69 \%$ to $60 \%$ after treatment with a Bruno disc refiner to $100 \mathrm{ml} \mathrm{CSF}$ for the bleached Eucalyptus urogandis kraft pulp. In our experiment, however, there were very small changes in the crystallinities of all four samples treated by the PFI mill and by Valley beater refining, as shown in Fig. 4.
This result might be attributed to the fact that the crystallinities of the samples changed within the range of experimental error because of the lower refining level (300 ml CSF) employed for the wood pulps. The mean crystallinity index of softwood began at $73.2 \%$ and ended at $73.0 \%$ after 170 minutes of Valley beater refining. However, for cotton linters, little change was shown at low freeness level (100ml CSF) by refining. For Cotton 1 , the crystallinity index began at $84 \%$ and ended at $83 \%$ after 45 minutes of Valley beater refining.

\subsection{Effects of PFI mill on strength properties of pulp handsheets}

Fig. 5 shows the increased tensile index of all four samples. The highest tensile index was obtained from the softwood fibers. From an initial value of 21.7 $\mathrm{Nm} / \mathrm{g}$, it sharply increased to $66.5 \mathrm{Nm} / \mathrm{g}$. The index of the hardwood sample also increased quickly at first 


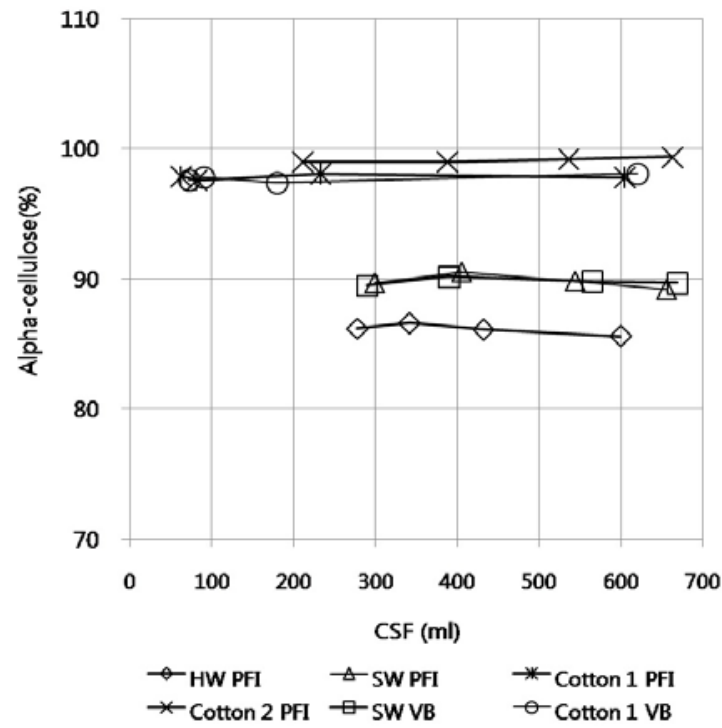

SW PFI: Softwood refined by PFI mill SW VB: Softwood refined by Valley beater Cotton 1 VB: Cotton linter 1 refined by Valley beater HW PFI: Hardwood refined by PFI mill Cotton 1 PFI: Cotton linter 1 refined by PFI mill Cotton 2 PFI: Cotton linter 2 refined by PFI mill

Fig. 3. Effect of PFI mill and Valley beater refining on alpha cellulose contents.

and then slowly increased after 10 minutes of refining. Its tensile index reached $51.9 \mathrm{Nm} / \mathrm{g}$ from a starting point of $19.5 \mathrm{Nm} / \mathrm{g}$. The lowest tensile index in this research was obtained for Cotton 1. Its initial tensile index of $7.6 \mathrm{Nm} / \mathrm{g}$ reached $21.4 \mathrm{Nm} / \mathrm{g}$ after Valley beater refining. In general, an increase in a paper's tensile strength properties is due to an increase in the fiber flexibility and fiber surface area. It seemed that the increase in fiber flexibility and fiber surface area produced by refining with the PFI mill and Valley beater refining had no effect on the cellulose DP, alpha-cellulose content, or cellulose crystallinity as long as the refining level was not extreme. The tensile strength of samples treated by the Valley beater and PFI mill increased following the same pattern. However, the rate of strength development of the softwood fibers refined by the Valley beater was much

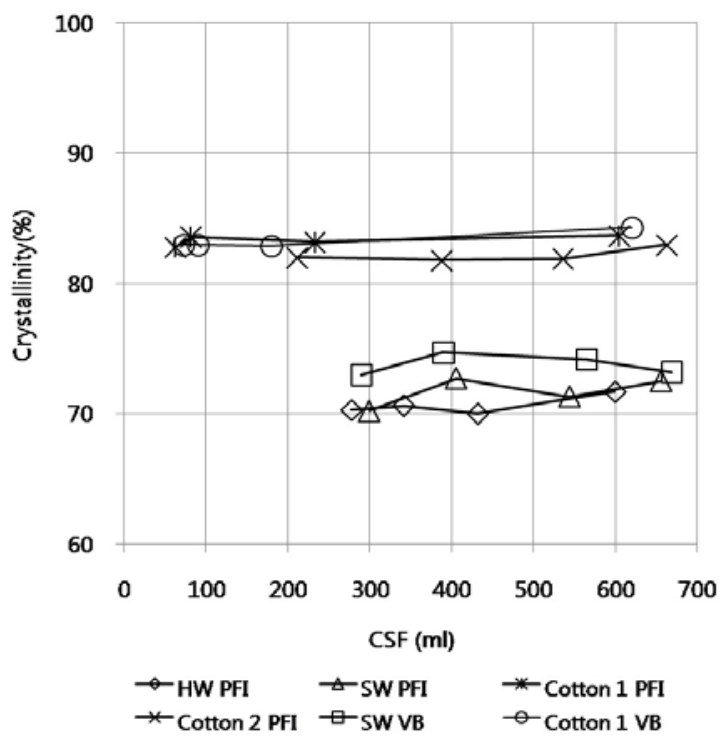

ISW PFI: Softwood refined by PFI mill SW VB: Softwood refined by Valley beater Cotton 1 VB: Cotton linter 1 refined by Valley beater HW PFI: Hardwood refined by PFI mill Cotton 1 PFI: Cotton linter 1 refined by PFI mill Cotton 2 PFI: Cotton linter 2 refined by PFI mill

Fig. 4. Effect of PFI mill and Valley beater refining on crystallinity.

faster at first but then sharply decreased at the same rate as that of PFI mill refining (Fig. 5).

\section{Conclusion}

There was very little change, if any, in the fiber length, CED viscosity, crystallinity index, or alphacellulose content of bleached wood fibers and cotton fibers subjected to PFI mill refining at a medium (10\%) consistency until their freeness levels decreased to around $300 \mathrm{~mL}$ CSF for wood fibers and around 100 $\mathrm{mL}$ CSF for cotton fibers. Valley beater refining at a low (1.5\%) consistency induced severe cutting in low-strength cotton fibers, which had a low CED viscosity. This loss of fiber length down to half of the original fiber length, however, did not cause a noticeable change in CED viscosity, crystallinity index, or alpha- 


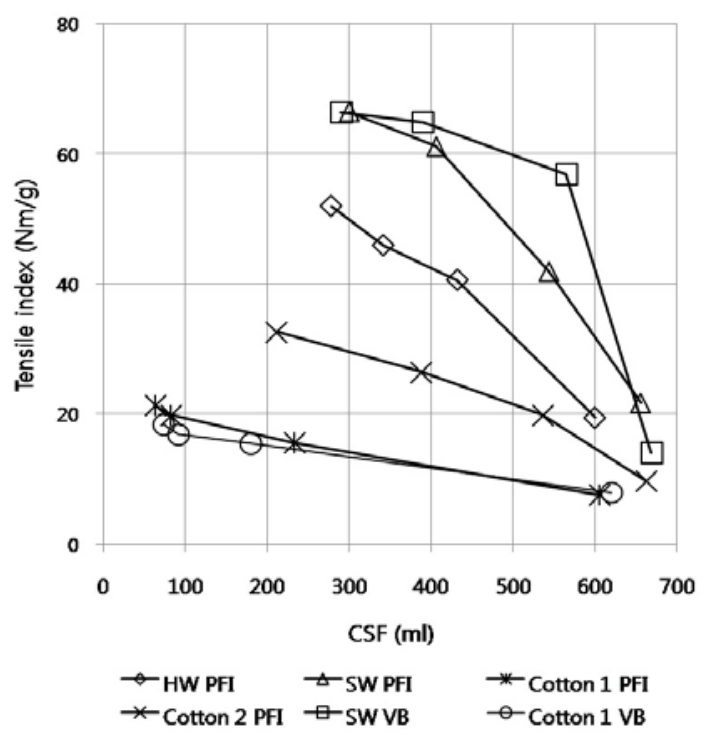

SW PFI: Softwood refined by PFI mill SW VB: Softwood refined by Valley beater Cotton $1 \mathrm{VB}$ : Cotton linter 1 refined by Valley beater HW PFI: Hardwood refined by PFI mill Cotton 1 PFI: Cotton linter 1 refined by PFI mill Cotton 2 PFI: Cotton linter 2 refined by PFI mill

Fig. 5. Effect of PFI mill and Valley beater refining on tensile index of samples.

cellulose content. The tensile strength properties of handsheets were increased by the refining process, which increased the fiber surface areas and fiber flexibility. Therefore, it can be said that the exposure of new surface area and the delamination of the cell walls caused by the refining action had very little change on the CED viscosity, crystallinity index, or alpha-cellulose content until the freeness decreased to around $300 \mathrm{~mL}$ CSF for wood and $100 \mathrm{~mL}$ CSF for cotton fibers.

\section{Acknowledgement}

This research was supported from the 2010 R\&D program (Project No. 10035477) funded by the Ministry of Knowledge and Economy of the Korean Government.

\section{Literature cited}

1. Lumiainen, J., Refining of chemical pulp,chapter 4, Paper making part 1, Stock preparation and wet end, Paper making science and Technology, Paulapuro, $\mathrm{H}$. (ed.), Finnish Paper Engineers' Association and TAPPI, pp.92-130 (1999).

2. Gandini, A. and Pasquini, D., The impact of celluloses fiber surface modification on some physic-chemical properties of the ensuing papers, Industrial Crops and Products 35: 15-21 (2012).

3. Chen, Y., Wan, J., Zhang, X., Ma, Y.and Wang Y.,Effect of beating on recycled properties of unbleached eucalyptus cellulose fiber, Carbohydrate Polymers 87:730-736 (2012).

4. Tonoli, G.H.D., Teixeira, E.M., Correa, A.C., Marconcini, J.M., Caixeta,L.A., Pereira-da-Silva, M.A. and Mattoso, L.H.C., Cellulose micro/nanofibers from eucalyptus kraft pulp: preparation and properties, Carbohydrate polymers 89: 80-88 (2012).

5. Wertz, J.L., Bédué, O. and Mercier, J.P.,Fundamental Sciences, Cellulose Science and Technology, Chapter 3 , Structure and Properties of Cellulose, Fundamental Science, EPFL Press, pp.130-132 (2009).

6. Abril, A., Rodríguez, M., Sánchez, A. and Baños, D., Cotton linter and Kraft bleached pulps mixture in the production of artistic paper. Cuba, Congress in pulp and paper research (2002).

7. El-Ghany, N.A., Highly reactive cotton linters from refining of prehydrolysed AQ-soda pulp. Cellulose Chemistry and Technology 44: 255-264 (2010).

8. Waterhouse, J.F., IPST Technical Paper series number 649, Institute of Paper Science and Technology, Atlanta, Georgia, 4th international refining conference, Palazzo dellaFonte, Fiuggi, Italy, p.10 (1997).

9. Kim, U.J., Eom, S.H. and Wada, M., Thermal decomposition of native cellulose: Influence on crystallite size. Journal of Polymer degradation and stability 95:778-781 (2010).

10. Wertz, J.L., Bédué, O. and Mercier, J.P., Fundamental Sciences, Cellulose science and Technology, Chapter 6, Non-biological Degradation of Cellulose, EPFL Press, p. 258 (2010). 